\title{
PRE-HOSPITAL RESUSCITATION OF CHILDREN IN THE CITY OF PRAGUE BETWEEN 2003 AND 2015
}

VESELÁ Katarína, FRANĚK Ondřej, PEŘAN David Prague Emergency Medical Services

\section{Introduction}

While there is a lot of studies dealing with out out-of-hospital cardiac arrest (OHCA) in adults, data about OHCA in children age ( $\mathrm{CH}-\mathrm{OHCA})$ are rarely published. The aim of this study is to describe epidemiology and results of $\mathrm{CH}-\mathrm{OHCA}$ in City of Prague (1,2 million of inhabitants).

\section{Methodology}

Retrospective analysis of epidemiology and survival rates of $\mathrm{CH}-\mathrm{OHCA}$ during 13 years period from 2003 to 2015 . The data are taken from Prague OHCA Utstein-style database. Children age was defined as age from 0 to 17,99 years.

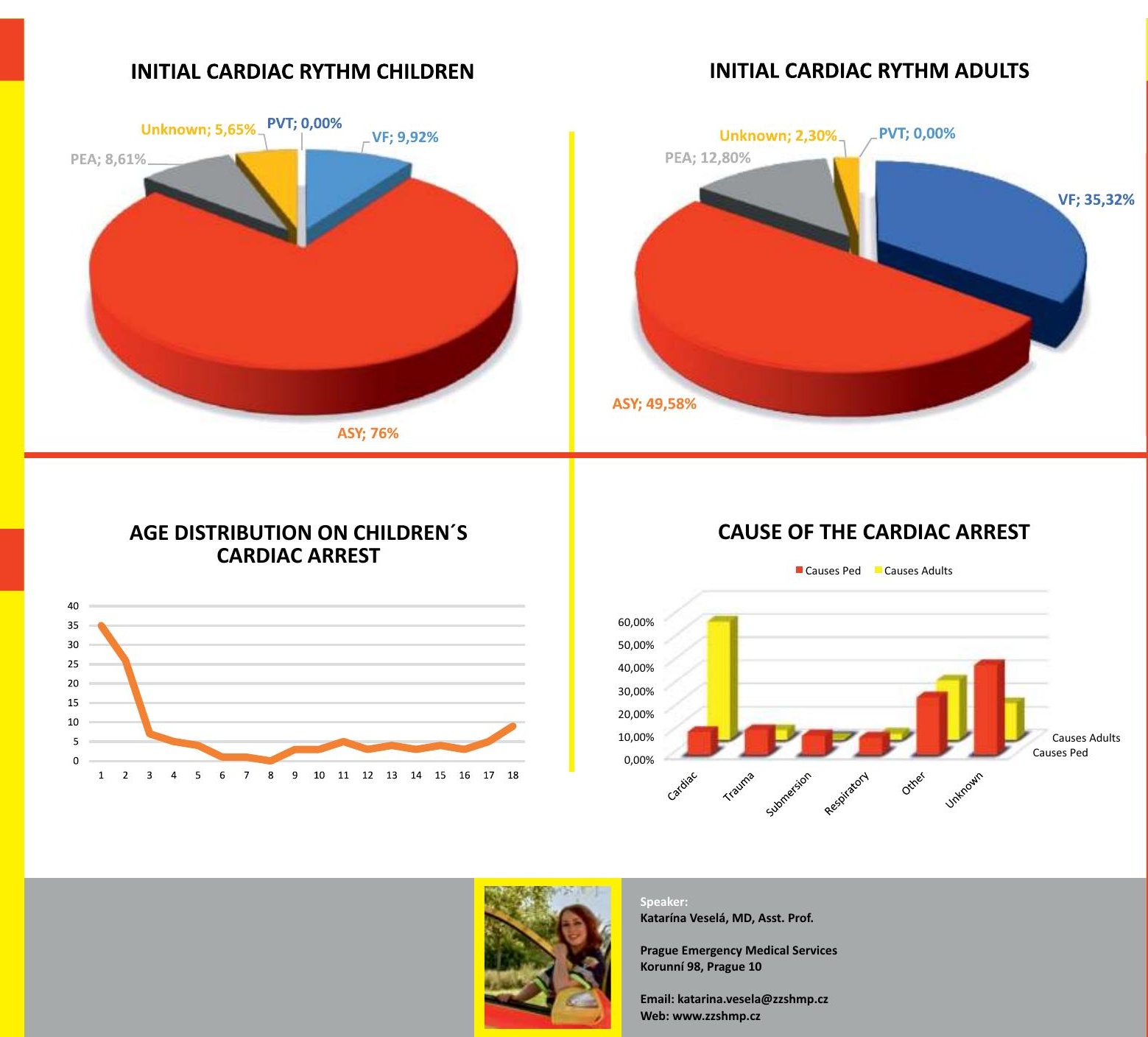

\section{Results}

In the study period, there were 6626 OHCAs attended by Prague EMS, of which 121 met the criteria of $\mathrm{CH}-\mathrm{OHCA}(1.8 \%, 0.78 \mathrm{CH}-\mathrm{OHCA}$ per 100.000 inhabitants and year). The majority of $\mathrm{CH}-\mathrm{OHCA}$ occurred in age groups $0-0.99(35 ; 28.9 \% ; p<0.05)$ and $1-1.99(26$ $21.5 \% p<0,05)$. In no other age group the number of $\mathrm{CH}-\mathrm{OHCA}$ exceeded $9(\mathrm{n} / \mathrm{s})$.

No $\mathrm{CH}-\mathrm{OHCA}$ was witnessed by ambulance personnel. Layperson CPR was performed in 95 cases $(78,5 \%)$. Full BLS was delivered in 36 cases $(37,9 \%)$, while in 59 cases $(62,1 \%)$ compressions-only CPR was provided.

The first captured rhythm was most often asystole (96; 79.4\%). Ventricular fibrillation (VF-first subgroup) as the first rhythm was present in 12 patients $(10.0 \%)$, half of whom were $15+$. The most common cause of $\mathrm{CH}$ OHCA was recorded as unknown (39\%). The overall survival rate from $\mathrm{CH}-\mathrm{OHCA}$ (with CPC $1-2$ ) was $10.7 \%$, in VF-first subgroup it was $41.7 \%$ 